\title{
La clase incorporada: cuerpo, lenguaje y distancia en el dispositivo médico
}

LUC BOLTANSKI (2008). As classes sociais e o corpo.

São Paulo: Paz e Terra, 179 pp.

As classes sociais e o corpo, libro escrito por el sociólogo francés Luc Boltanski, consta de dos partes, cada una el resultado de investigaciones diferentes. La primera parte se titula «El descubrimiento de la enfermedad, la difusión del conocimiento médico». Esta se basa en un estudio con amas de casa de diferentes clases sociales, quienes fueron entrevistadas sobre el cuerpo y la salud. La segunda parte del libro, titulada «Los usos sociales del cuerpo», se desprende de un trabajo realizado en el Centro de Sociología Europea bajo la dirección de Pierre Bourdieu. Este se basó en el análisis de estadísticas oficiales y no oficiales sobre diversos campos ligados a la sociología del cuerpo: el consumo médico, el alcoholismo, la higiene, la sexualidad, la alimentación, los deportes, la belleza, entre otros.

En ambas partes del libro, el cuerpo es presentado como una construcción social, por ello el autor intenta analizar la noción de cuerpo que se pone en juego en las diferentes clases sociales. Fundamentalmente trata de explicar la relación que los sujetos establecen con la salud y con los profesionales encargados de ayudar a mantenerla o «repararla» cuando está en riesgo (los médicos), argumentando que la clase social, el lenguaje y la concepción del cuerpo construida por los sujetos son elementos determinantes para el éxito o fracaso de esta relación. 


\section{La noticia de la enfermedad y la distancia de clase}

La primera parte del libro consta de tres capítulos en los que el autor aborda y desarrolla tres temas fundamentales: la medicina popular y la medicina científica, la relación enfermo-médico y la emisión del discurso sobre la enfermedad.

El capítulo primero estudia la tensión entre medicina popular (o familiar) y medicina científica. En él se diserta respecto al discurso médico hegemónico, argumentando cómo este pertenece exclusivamente a los médicos, pues son ellos quienes están autorizados para ejercer y hablar de la medicina. Sin embargo, tal estatus siempre está en pugna con el saber común, saber que, en la investigación, fue «rastreado» mediante la exploración del conocimiento que las madres de las clases populares y medias bajas, han desarrollado respecto a las enfermedades que padecen sus hijos. Estas madres suelen reconocer los síntomas mediante el «análisis» del comportamiento de los niños, a través del dolor físico y cuando presentan cuadros febriles. Con estos elementos es conceptualizada la enfermedad, dividiendo las enfermedades en: climáticas, digestivas e infantiles.

Para Boltanski, estas habilidades constituyen una «medicina imitativa», puesto que las madres se «contentan» con reproducir el discurso del médico, usando las palabras y gestos que logran comprender. Estas prácticas muestran la presencia simbólica del médico en la medicina popular/familiar, y cómo el discurso construido respecto al cuerpo y la salud está estrechamente relacionado con el saber hegemónico, que a su vez entra en diálogo (tensión) con el saber popular y la medicina tradicional. Los sujetos se encuentran, pues, en medio de dos tipos de medicina. Esto supone para ellos un esfuerzo por decidir entre el peso histórico, simbólico y cultural del saber popular y la «efectividad» y pragmatismo de la biomedicina.

Otro aspecto resaltado por el autor en este capítulo, se refiere al papel de la escuela en la reproducción de la brecha entre las clases populares y el saber científico. Las clases populares son educadas para que respeten la ciencia y la conciban como inalcanzable, se busca que sus miembros sean «conscientes» de su ignorancia y se subordinen frente al saber médico-científico. Este reconocimiento de la distancia dificulta, para los sujetos, la elaboración de un discurso coherente respecto a su cuerpo y sus enfermedades, favoreciendo, además, que sientan vergüenza de usar el lenguaje de la medicina para explicar sus síntomas.

Reconocer la legitimidad de la biomedicina redunda en ansiedad y tensión para estos sujetos, que, incapaces de explicar(se) su enfermedad, terminan por someterse a lo que el otro impone, renunciando a las certezas que hallaban en la medicina popular. Por ello el autor afirma: 
los miembros de las clases populares están hoy frente a la medicina y los médicos como frente a un universo extraño que, de la misma manera que el capitalismo, según Max Weber, preexiste a los individuos y les impone su lenguaje y sus reglas (29).

Esta alusión al capitalismo no trasciende al resto de la obra, sin embargo, cabe destacar lo oportuna que resulta para tratar de comprender la posición que ocupa el sujeto respecto a la biomedicina, en cuanto esta tiende a reificarlo, imponiéndole incluso lo que debe sentir y cómo sentirlo, es decir, tratando de dotar de significado al cuerpo del enfermo, desestimando lo construido por él.

El segundo capítulo trata de describir y analizar los avatares propios de la relación enfermo-médico. El lenguaje constituye el eje central de la discusión, pues como ya se mencionó, los pacientes de las clases populares tienen dificultades para expresar con coherencia sus padecimientos. Los miembros de estas clases tienden a valorar la relación que establecen con los médicos según la buena voluntad y la dedicación que se les profese; esto se debe, argumenta el autor, a que estos sujetos no tienen las herramientas cognitivas necesarias para reconocer las capacidades profesionales del médico.

En esta distancia lingüística, Boltanski ubica la gran diferencia entre clases respecto al servicio médico y la salud en general. Para él, la pobreza ideo-verbal, manifiesta en las clases populares, disminuye la calidad de la escucha y el interés por parte de los médicos, lo que produce que estos den explicaciones ceñidas al lenguaje técnico que mantienen la falla comunicativa. «Esta investigación mostró que la proporción de aquellos que declaran que el médico no les da bastantes explicaciones, aumenta considerablemente cuando se pasa de las clases superiores a las clases populares» (37). Los médicos, «conscientes» también de la «incapacidad» de comprender que aqueja a los miembros de las clases bajas, consideran imperioso imponer las medidas a seguir para reestablecer la salud, por ello reclaman confianza «casi ciega» frente a sus apreciaciones.

Para el autor, lo que el médico pone en juego son estrategias y técnicas que favorecen la relación asimétrica reconocida por ambos, el enfermo se hace objeto pasivo y el médico lo manipula física y moralmente. Por ello la consulta suele convertirse en un monólogo donde el médico dirige, según su parecer, una conversación que debería centrarse en la palabra del enfermo. De hecho, lo que el paciente manifiesta suele ser desestimado durante el encuentro, pues su saber es puesto en duda y su ignorancia es develada constantemente. Estas son «técnicas de manipulación» que van acompañadas de «actitudes particulares» que implican la infantilización del enfermo; una de estas técnicas es el tono de la voz durante la consulta: esta suele ser cortante y fuerte, con entonaciones marcadas y transmitiendo órdenes fijas y concretas. 
Así pues, hay aspectos simbólicos y materiales que obstaculizan el establecimiento de relaciones terapéuticas más simétricas. Esto explica, además, el papel preponderante que la figura del curandero ocupa en las clases populares. Estos, desde su cosmovisión, explican al enfermo las «razones» de su padecimiento y lo hacen mediante un lenguaje accesible, puesto que comparten las mismas representaciones y los mismos códigos lingüísticos al pertenecer a la misma clase social. Sin embargo, para las clases populares, los curanderos y los médicos no son figuras antagónicas, ambas especialidades pueden coexistir y reportar beneficios.

El capítulo tercero se concentra en la emisión del discurso sobre la enfermedad, continuando con los intereses de los capítulos precedentes. Aquí el autor argumenta que los médicos no hacen nada para mejorar la comunicación con las clases populares, lo que condena a estas últimas a reconstruir el discurso con base en el malentendido y la pobre información que se les brinda.

Se hace necesario, pues, indagar sobre las reglas que permiten la construcción de las representaciones populares de la enfermedad, entendiendo que hay una relación dialéctica entre lo popular y lo científico, y que las representaciones producidas tienen carácter colectivo más allá de que se expresen en lo individual. Por ello, las clases populares sustituyen el discurso médico por uno más «amable» que se instala en los criterios de los que ellos disponen. El autor rastrea esta «reducción analógica» indagando sobre lo que dicen las clases populares a propósito del origen de la enfermedad. Para estas clases, las enfermedades suelen ser descritas como hereditarias (propias del individuo, inevitables y fatales)-que «siguen la sangre»-, o contagiosas (venidas del exterior). Por otro lado, en las clases superiores, se distingue entre congénito e infeccioso, es decir, se usan términos más cercanos a la biomedicina.

Finalmente, el autor argumenta que antes de estudiar el discurso subjetivo de la enfermedad, es preciso examinar las condiciones objetivas de su producción. Es por ello que analiza las posiciones simbólicas y materiales de los diferentes actores implicados.

\section{Cuerpo y comportamiento}

La segunda parte de la obra versa sobre las diferentes disciplinas que se ocupan del cuerpo desde perspectivas e intereses diversos. Según el autor, estas buscan dominar el cuerpo en situación, «moralizándolo y domesticándolo», por lo que suelen reducirlo a una sola de sus propiedades. Se plantea que estas disciplinas responden al capitalismo y sus demandas sociales, atendiendo a teorías funcionalistas del cuerpo.

Por lo tanto, en la obra se analiza la relación de causalidad entre el tipo de relaciones objetivas a las cuales están sometidos los sujetos y el tipo de «comportamiento 
corporal» anudado a sus hábitos de clase. Entonces, ocupándose de las variaciones del consumo médico según las diferentes clases sociales, se abordan cuatro aspectos clave: la necesidad médica, la competencia médica, la cultura somática y el uso del cuerpo.

Para empezar, se indaga sobre la naturaleza y las condiciones de posibilidad de la necesidad médica, erigiéndose el consumo médico como un producto dependiente de la concepción y el uso que los sujetos le dan a su cuerpo. Para Boltanski, en las clases populares se suele correr más riesgos y sus miembros se someten en menor medida a la medicina preventiva. Esto se debe, por un lado, a sus condiciones materiales, y, por otro lado, a lo poco que se reflexiona respecto al cuerpo.

El autor insiste nuevamente en la importancia del lenguaje, sosteniendo que la forma en que este se usa para expresar la enfermedad ayuda a configurar la experiencia de los sujetos. En este sentido, ningún discurso a propósito del padecimiento debe ser desestimado por cuanto es útil para comprender la experiencia subjetiva de quien enferma y su relación con el propio cuerpo y el mundo circundante.

Sin embargo, lo que encuentra Boltanski es que la intensidad de las relaciones entre enfermos y médicos desmejora según la escala social, en otras palabras, cuanto más baja la clase social menos explicación y justificación de parte del médico y más silencio de parte del paciente. Por esta razón, la relación terapéutica se transforma en una de dominación, lo que produce que las clases populares tengan mayores dificultades para memorizar y reproducir la terminología científica usada por el médico, y obstaculiza la resignificación del cuerpo y la concepción de salud. La experiencia de enfermar se hace entonces más «amplia e inaprehensible», más difícil de comprender y explicar.

En razón del discurso biomédico, se invalidan otros discursos y saberes, ya que se desconoce el papel del sentido común y la medicina tradicional en la configuración de la experiencia de la enfermedad, es decir, se desprecia la historia de los sujetos, sin considerar que en ella hay insumos pertinentes para reconocer aspectos que van desde las condiciones objetivas y subjetivas que favorecieron el advenimiento de la enfermedad, hasta sus posibilidades actuales de afrontar la misma.

Así, es posible argumentar que el silencio en la consulta responde, no a la incapacidad de usar la palabra, sino a la lógica de dominación que anula la dimensión subjetiva de la enfermedad dentro del dispositivo médico, para preservar, por un lado, el funcionamiento burocrático del sistema, y, por otro lado, el semblante imperturbable y sapiente que el médico proyecta, pues lidiar con el padecimiento subjetivo le sacaría de su registro, demandando de él que hable menos y escuche más (además, alargaría el tiempo de la consulta).

Respecto a la cultura somática, Boltanski se refiere a cómo las diferentes clases sociales se relacionan con el cuerpo. Las clases altas, por ejemplo, suelen prestarle 
mayor interés y atención y demandan de él bienestar y buen funcionamiento; por lo tanto, el cuerpo es «pensado y escuchado» con más detenimiento. Esto es ilustrado por el autor cuando muestra que las élites tienen menos prejuicios frente a la sexualidad, mientras en las clases populares es difícil distinguir lo educativo de lo obsceno, o cuando refiere que en las clases populares se presta menos atención a las partes del cuerpo que permanecen escondidas, y que «la presentación de la persona» está más institucionalizada (hay días y fechas especiales para cuidar la estética del cuerpo).

El trabajo también ocupa un espacio fundamental como productor de las representaciones que los sujetos elaboran respecto al cuerpo; en las clases populares se da relevancia a la resistencia y la fuerza, puesto que sus prácticas laborales suelen requerir estas habilidades. Esto explica porqué las personas son más renuentes a asistir al servicio médico, especialmente a la medicina preventiva, y dan más importancia a la alimentación, aunque esta no sea saludable, al asumir que lo importante es que aporte la energía necesaria para soportar las exigencias físicas que la cotidianidad impone. Por su parte, los miembros de las clases superiores adoptan medidas preventivas frente a la enfermedad y someten su cuerpo a reglas que buscan preservar la salud, mediante la higiene y el cumplimiento de las reglas del «buen vivir» y exaltando la importancia y los beneficios de una adecuada alimentación (saludable).

Es debido a estas concepciones contrapuestas respecto al cuerpo y la salud, que las expectativas frente al servicio médico varían: en las clases superiores los pacientes esperan consejos, mientras en las clases populares demandan fármacos, pues el tratamiento médico para ellos «es por excelencia violento, rápido y doloroso, mas actúa inmediatamente» (150). Este «sometimiento» al dolor y el sufrimiento en busca de la cura inmediata, permite comprender dos aspectos: 1) que para las clases populares el cuerpo debe responder a necesidades que no dan espera; y 2) la efectividad de la violencia simbólica que se pone en juego en la relación médico-enfermo.

\section{A modo de cierre}

La obra comentada permite, desde una perspectiva específica, analizar la relación entre cuerpo y clase social para dilucidar dos aspectos fundamentales: 1) las formas en que se configuran los conceptos de cuerpo y salud; y 2) el uso que se le da al cuerpo según la relación dialéctica entre el sujeto y sus posibilidades sociales y materiales.

Boltanski se refiere a las maneras en que la posición social se incorpora en los sujetos, y desde ahí logra describir y analizar diferencias esenciales entre los miembros de cada clase. Estas diferencias pueden clasificarse en tres categorías que aluden a «cómo es concebido el cuerpo»: las expectativas, las demandas y la atención que se le 
presta. Para el autor, la relación que se establece con el cuerpo está estrechamente relacionada con los capitales ofrecidos y valorados por cada clase social. Así, para las clases populares, el cuerpo constituye una suerte de capital material, mientras para las clases superiores es más un capital simbólico. Por ello los primeros se ocupan de asuntos más «prácticos» y los segundos de asuntos más estéticos, como la forma de presentarse ante los otros.

Finalmente, es preciso mencionar que el discurso médico hegemónico reproduce y ahonda las desigualdades sociales, puesto que se deja permear por la distancia entre las clases, imponiéndose de manera violenta frente a los de menor posición social y desconociendo las condiciones objetivas que configuran el discurso construido por los sujetos. Como consecuencia de esto la palabra del sujeto es anulada, este es reducido a los parámetros orgánicos que describen su enfermedad y prevalece el modelo positivista de la medicina, el cual niega la posibilidad de diálogo con cualquier saber tradicional. 